\title{
Morphological and Numerical Characteristics of the Southern Chinese Dentitions. Part III: Anomalies in the Primary Dentition
}

\author{
Nigel M. King*,1, S. Tongkoom ${ }^{2}$ and H.M. Wong ${ }^{3}$ \\ ${ }^{I}$ Professor in Paediatric Dentistry, Faculty of Dentistry, The University of Hong Kong, Hong Kong SAR, China \\ ${ }^{2}$ Formerly postgraduate student in Paediatric Dentistry, Faculty of Dentistry, The University of Hong Kong, Hong Kong \\ SAR, China \\ ${ }^{3}$ Assistant Professor in Paediatric Dentistry, Faculty of Dentistry, The University of Hong Kong, Hong Kong SAR, \\ China
}

\begin{abstract}
Aim: To investigate the prevalence of eight morphological and numerical anomalies in the primary dentition of southern Chinese and to compare the prevalences with those from different ethnic groups.

Materials and Methods: The material used in the study consisted of plaster casts and standardized panalipse radiographs collected from 936 randomly selected 5-year-old children (493 males and 443 females) in Hong Kong. The anomalies, hyperdontia, hypodontia, macrodontia, microdontia, double tooth, talon cusp, dens invaginatus and taurodontism, were assessed using diagnostic criteria that have been most often been cited in the published literature.

Results: Of the eight dental anomalies examined, microdontia was the most common and occurred in $6.3 \%$ of southern Chinese children. This prevalence figure was much higher than that of other ethnic groups and it was mainly due to microdontia of the maxillary canines $(4.3 \%)$. The prevalence of hypodontia (4.1\%) was also the highest of all races, of which mandibular lateral incisors were the most frequently missing teeth in the southern Chinese (3.2\%). Of the other dental anomalies studied, the prevalence of hyperdontia $(2.8 \%)$ and double tooth $(4.1 \%)$ were higher than reported for Caucasians.
\end{abstract}

Conclusion: Higher prevalences of microdont maxillary canines, and missing lateral mandibular incisors can be considered to be characteristics of the southern Chinese primary dentition.

Keywords: Dental anomalies, Primary dentition, Southern Chinese.

\section{INTRODUCTION}

Dental anomalies can be broadly considered as being morphologic and numeric. If anomalous is taken to mean an irregularity of the norm, then a dental anomaly is a feature of the dentition that can be expected to occur in the minority of a given population. Anomalies of the dentition hold a fascination for many dentists, more especially for those who practice Paediatric Dentistry. The presence of dental anomalies of the teeth and the likely causes may be more possibly thought provoking than features with profound consequences upon the affected dentition.

Studies of the primary dentition have reported the prevalence of morphological and numerical variations in Scandinavian [1], Japanese [2-4], north American [5, 6] and British populations [7]. However, no research has been reported on the Chinese population. Hong Kong is geographically situated on the south coast of China and is one of the most densely populated areas in the world. Most of the population are of southern Chinese origin. Therefore, it was considered

*Address correspondence to this author at the Paediatric Dentistry, Faculty of Dentistry, The University of Hong Kong, 2/F, Prince Philip Dental Hospital, 34 Hospital Road, Hong Kong SAR, China; Tel: +852 28590253;

Fax:+852 25593803; E-mail: profnigelking@mac.com to be of great value to gather baseline data on the prevalence of morphological and numerical variations in the primary dentition of Chinese children in Hong Kong.

The published literature on dental anomalies in the permanent dentition suggests that variation exists between racial groups and even sub-racial groups. By comparing published data from various populations including part I of this series, it is evident that higher prevalences of double tooth, dens evaginatus and missing mandibular incisors are characteristics of the southern Chinese permanent dentition. Although the published literature on anomalies in the primary dentition is limited, and the prevalence is lower than in the permanent dentition, it seems that variation in the primary dentition may also exist between racial groups. Such anomalies are of interest in anthropology because they serve as characteristics of a population thus making it distinguishable from other ethnic groups.

The aims of this study were to determine the prevalence of the various dental anomalies, such as hyperdontia, hypodontia, macrodontia, microdontia, double tooth, talon cusp, dens invaginatus and taurodontism in the primary dentition of the five years old southern Chinese children in Hong Kong. By comparing these data with those on other populations, it was intended to determine if the primary dentition of 
the southern Chinese has any features that may characterize this dentition.

\section{MATERIALS AND METHODS}

\section{Study Sample}

The sample frame was designed with the co-operation of the staff of the statistics section of the Education Department of Hong Kong. The target population was 5 years old southern Chinese children who attended kindergartens in Hong Kong. A stratified two-stage cluster sampling design was constructed for this survey. A random number generator was used to select a kindergarten and all of the 5 years old children in that kindergarten were then invited to participate in this survey. The chance of a particular kindergarten being chosen was proportional to the number of 5 years old children attending the kindergarten. No socio-economic classification was attempted. Approval to conduct this study was received from the Ethics Committee, Faculty of Dentistry, the University of Hong Kong. Prior to the examination, written consent was obtained by letter from the parents of the randomly selected 1,005 children via the school staff. Participation in the study was strictly voluntary.

\section{Method of Examination}

The children were transported, under escort, to the Prince Philip Dental Hospital. Their dental histories were taken and the clinical caries status (dmft) was recorded. Irreversible hydrocolloid alginate (Jeltra, L.D. Caulk Co., Milford, D.E., U.S.A) impressions were then taken of the children using standard perforated trays (TP Orthodontics, Inc., Alaska, Indiana, U.S.A.). Immediately after the impression had been taken, they were poured in hard stone to minimize the distortion. The children then had a standard panoral radiograph taken using a Panelipse machine (General Electric Company, U.S.A.); this was supplemented by a standard anterior occlusal radiograph, using an orientation frame and spirit level to standardize the angle to the horizontal, for those subjects who were suspected of having hyperdontia, dens invaginatus, macrodontia or double tooth anomalies. All of the radiographs were taken by professional radiographers in the Oral Radiology Unit, the Prince Philip Dental Hospital.

In the study cast examination, individual teeth on the casts were examined under an illuminated magnifying glass (x3) to diagnose the presence or, absence of an anomaly. The illustrated versions of the various classifications of the eight anomalies, and a list of the teeth upon which they can be expected to occur, was prepared to enhance the accuracy of the diagnoses and to maintain the level of examiner reliability. The reasons for omitting some teeth from the investigation were: (i) poor quality or of the study cast; (ii) chipped or broken teeth; (iii) wear or attrition; (iv) gross caries; and (v) restorations.

Examination of all of the radiographs was conducted in a darkened room using an illuminated viewing box. When a diagnosis of double tooth was made, the number of pulp chambers and root canals were also recorded. A diagnosis of hyperdontia was made only after examining both the panalipse and the upper occlusal films. If a supernumerary was present, the location, eruption status, orientation, shape of the crown and degree of root development were recorded. For diagnosis of taurodontism, all primary mandibular sec- ond molars were traced using acetate tracing paper and a pencil prior taking measurements. The distal (d) and mesial (m) points of the amelo-cemental junction were marked on the tracing of each tooth. Points " $\mathrm{d}$ " and " $\mathrm{m}$ " were then aligned and measurements made from this axis to two further points; " $\mathrm{f}$ " the highest point of the floor of the pulp chamber (measurement "a") and " $r$ " the apex of the distal root (measurement " $b$ "). The teeth were diagnosed as exhibiting taurodont when the $a: b$ ratio was $1: 4.5$ or less. The teeth were discarded from the evaluation when any of the points were indefinable, or when there was evidence of pathology.

Approximately $10 \%(n=93)$ of the casts and radiographs were randomly selected by a computer programme for reexamination. All of the examinations were conducted by one previously trained and calibrated examiner.

\section{Diagnostic Criteria}

There were eight dental anomalies which, according to the published literature, can be expected to found in the primary dentition:

Hypodontia:

Congenital absence of one or multiple teeth. Absence of a tooth was confirmed clinically and radiographically by considering the caries status and the presence of macrodontia or double tooth of any of the adjacent teeth.

Hyperdontia: A dentition with any additional tooth, or structure formed from a tooth germ.

Microdontia: It is considered to exist if one, or more teeth are smaller than those considered to be within normal range; that is, they are outside the usual limits of variation. For practical purpose this is a tooth that is 1 $\mathrm{mm}$ smaller than its antimere, or the mean dimension of that tooth [8].

Macrodontia: $\quad$ It occurs when a tooth, or teeth are larger than those considered to be within normal range; that is, they are outside the usual limits of variation. For practical purpose this is a tooth that is $1 \mathrm{~mm}$ larger than its antimere, or the mean dimension of that tooth [8], and exhibits normal crown, root and pulp morphology.

Double Tooth: $\quad$ A large tooth with incisal notching, labial or palatal grooving, or radiographic evidence of a separate or fused pulp chamber, or root was recorded as a double tooth. Furthermore, a double tooth is any tooth like structure which resembles two complete, or partially complete teeth [3, 9].

Talon Cusp: $\quad$ An additional cusp that projects from the singulum of an anterior teeth and extends at least half the distance from the cemento-enamel junction to the incisal edge [10].

Dens Invaginatus: An invagination of the odontogenic tissues, enamel and dentine towards the pulp of an incisor [11]. 
Taurodontism: A tooth is considered to exhibit taurodontism when the ratio between the vertical distances from the amelo-cemental junction to the floor of the pulp chamber, and the amelo-cemental junction to the apex of the roots of the mandibular second molar, is $1: 4.5$ or less [12].

\section{Prevalence Data Review}

In order to compare the prevalence data from this study with those of other studies the literature and data from studies published between 1930 and 2009, which were related to dental anomalies in the primary dentition, were sourced using PubMed and hand searches. The key words used for the PubMed searches were dental anomalies, primary dentition, hyperdontia, hypodontia, macrodontia, microdontia, double tooth, talon cusp, dens invaginatus and taurodontism. The reference lists of the articles retrieved from the electronic database were hand searched to identify additional articles that might provide information relevant to the objectives of this paper. It was impractical to perform a systemic review because the methodology used in the published studies varied, thus preventing valid statistical analyses.

\section{RESULTS}

Of the 1005 children who participated in this study, comprehensive records including good quality plaster casts and standardized panalipse radiographs were obtained from 936 children; 443 girls and 493 boys. The mean chronological age was $5.75(\mathrm{SD}=0.46)$ years for girls and $5.73(\mathrm{SD}=0.45)$ years for boys.

A total of 93 of the casts and radiographs were reexamined to measure the examiner reliability for the diagnoses of the various dental anomalies. The Kappa coefficients were in the range from 0.82 (macrodontia) to 1.00 (hypodontia and hyperdontia). Examiner reliability for the diagnoses of dens invaginatus and taurodontism could not be determined because none of the subject selected had these two anomalies.

Of the 8 dental anomalies, microdontia was the commonest and occurred in $7.7 \%$ of the girls and $5.1 \%$ of the boys
(Table 1). However, no children were found to have dens invaginatus or taurodontism in their primary dentitions. The comparison of the prevalence figures of the various dental anomalies observed in this study, with those in other studies are shown in Tables 2 to $\mathbf{6}$. The prevalence of hypodontia in the southern Chinese children (4.1\%) was higher than reported for other ethnic groups (Table 2). Mandibular lateral incisors were the most frequently missing tooth in this study $(3.2 \%)$, which was contrary to the data from other studies in which the maxillary lateral incisors were the most frequently reported missing teeth. The prevalence of microdontia in southern Chinese children was $6.3 \%$ which was much higher than data for other races (Table 4). The majority of the microdontia was diagnosed in the maxillary canines $(4.3 \%)$. Moreover, the prevalence figures of hyperdontia $(2.8 \%)$ and double tooth $(4.1 \%)$ in this survey were found to be higher than reported for Caucasians (Tables $\mathbf{3}$ and $\mathbf{5}$ ).

\section{DISCUSSION}

This study of a randomly selected representative sample was based on high quality plaster study casts and standardized panalipse radiographs supplement by clinical examinations, dental history, and anterior occlusal radiographs. Examining the casts and radiographs, rather than the actual teeth caused a slight loss of subjects $(6.8 \%, n=69$ in this study) because some children could not tolerate the taking of impressions and radiographs. However, the advantages were that all of the tooth surfaces could be observed easily and there were no time constraints, or co-operation problems to manage, as can occur during an oral examination of a young child. Although the findings for hypodontia, in this study, may have been weakened by the variation in the quality of the dental histories; the diagnosis of the congenital absence of a tooth was confirmed clinically and radiographically by considering the caries status and presence of macrodontia of the adjacent tooth in order to minimize inaccuracies. The accuracy of the diagnosis of hyperdontia would be expected to be less affected by the quality of the dental histories because it was assumed that the chance of early extraction of a supernumerary tooth was extremely low. The rarity of dens invaginatus and taurodontism in the primary dentition as indicated in the literature $[7,13]$ was confirmed by the

Table 1. The Mouth Prevalence of the Various Dental Anomalies in the Primary Dentition of 936 Five Years Old Southern Chinese Girls and Boys in Hong Kong

\begin{tabular}{|c|c|c|c|c|}
\hline Dental Anomaly & \multicolumn{2}{|c|}{ Girls $(N=443)$} & \multicolumn{2}{|c|}{ Boys $(\mathrm{N}=493)$} \\
\hline Hyperdontia & 6 & 1.4 & 20 & 4.1 \\
\hline Microdontia & 34 & 7.7 & 25 & 5.1 \\
\hline Double tooth & 20 & 4.5 & 18 & 3.7 \\
\hline Talon cusp & 4 & 0.9 & 1 & 0.2 \\
\hline Dens invaginatus & 0 & 0 & 0 & 0 \\
\hline Taurodontism & 0 & 0 & 0 & 0 \\
\hline
\end{tabular}


Table 2. The Prevalence of Hypodontia in the Primary Dentition in Published Studies

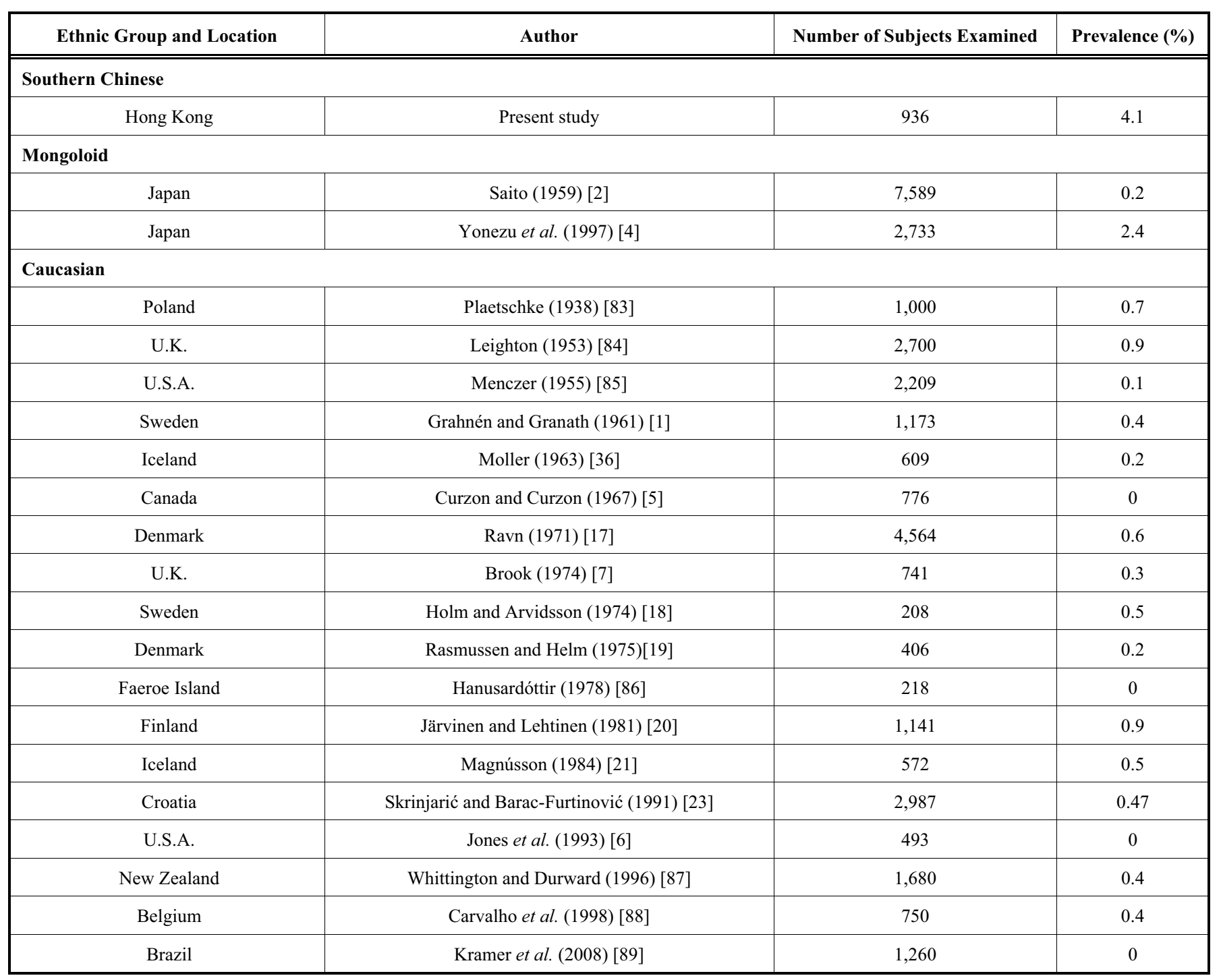

absence of any subject being affected in this study (Table 1). However, this could be partially attributed to the diagnostic criteria and the indistinctiveness of a panalipse radiograph in the anterior sextants.

Most of the published data on the inter-relationships between the different dental anomalies has been for the permanent dentition; however, this does not preclude the application of the model to the primary dentition. In this study, macrodontia occurred only in the primary mandibular incisors and canines, and especially when there was hypodontia of one tooth in that quadrant $(1.1 \%, n=10)$. This may be explained by the hypothesis that the different anomalies can occur in the same tooth group due to factors related to the developmental timing of the teeth. In this hypothesis, if the teeth, in a given segment, which develop earlier are larger, then those which develop later will tend to be smaller than normal, or even absent $[14,15]$. The other explanation is, that macrodontia is an expression of excess dental tissue to compensate for the lack of tissue as represented by a congenital missing tooth in that quadrant. Moreover, there were 7 children $(0.7 \%)$ in this study who had both hypodontia and double tooth. It is interesting to note that all of the cases of hypodontia occurred in the contra-lateral quadrant to double tooth anomalies, which is also a manifestation of the lack of dental tissue. The data from the present investigation appears to indicate that there are both inter- and intra- arch compensatory mechanisms, which somehow, regulate the total quantity of dental tissue within an arch of the primary dentition. These possible inter-relationship warrant further specific investigation.

The various anomalies will be discussed independently by first considering the physical characteristic, followed by the prevalence of that anomaly among different populations to identify any distinctive features in the data for the primary dentition of the southern Chinese.

\section{Hypodontia}

Hypodontia and congenital missing teeth are two general terms that have used to describe the congenital absence of teeth. The absence of one, or several teeth has been called oligodontia, agenesis of numerous teeth (commonly associated with specific syndromes or severe systemic abnormali- 
Table 3. The Prevalence of Hyperdontia in the Primary Dentition in Published Studies

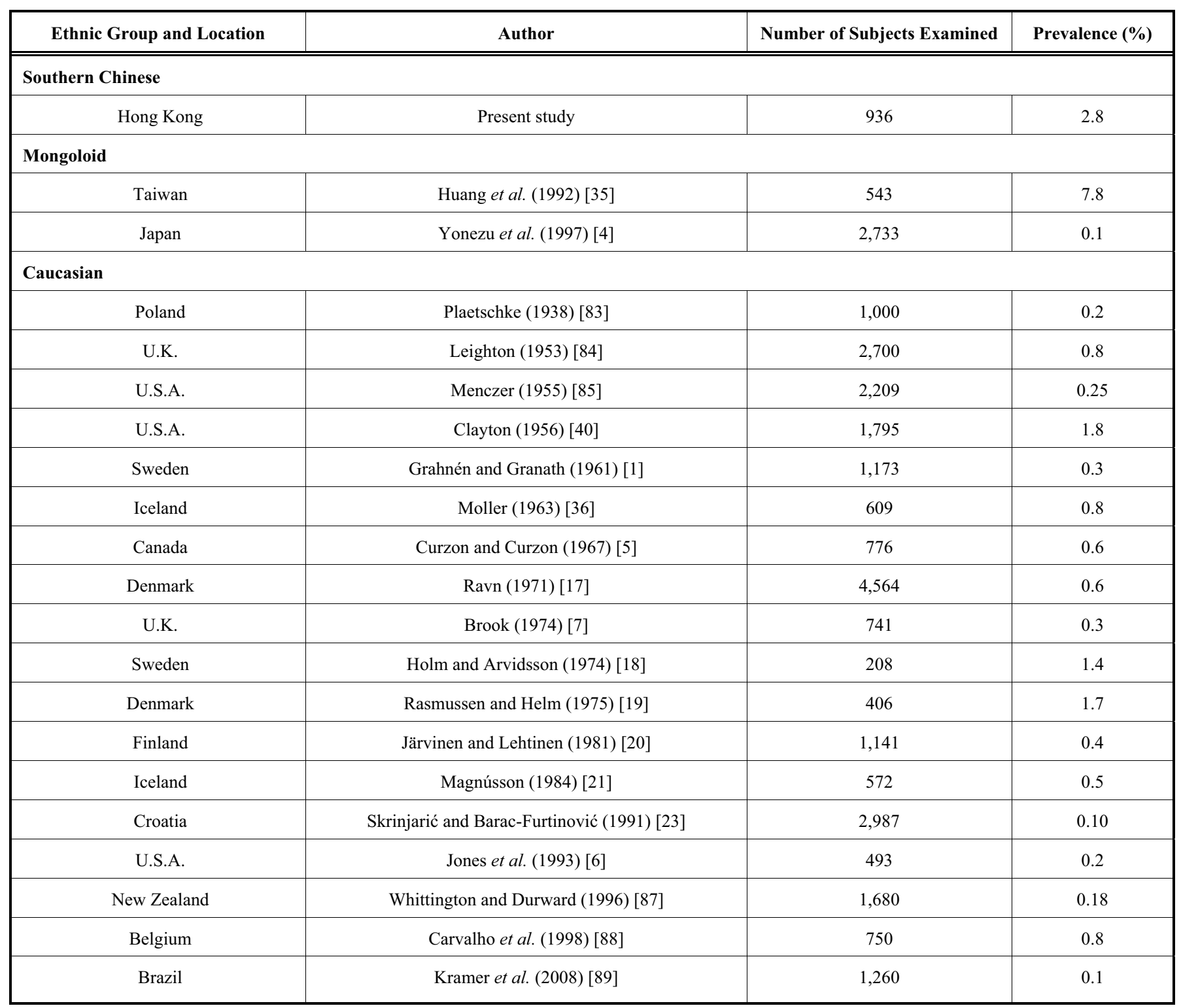

ties), while anodontia is an extreme expression of oligodontia indicating the total absence of dental structures [16]. Anodontia has been found to occur in the more severe forms of ectodermal dysplasia. To make a diagnosis of hypodontia, a dental history is necessary to eliminate the possibility of previous extraction of a normal tooth [7].

The prevalence of hypodontia was found to be higher in southern Chinese girls than boys (Table 1), which was in accordance with the findings of most investigators [1, 1721], but contrary to those of Brook [7] and Yonezu et al. [4]. In this study, congenital missing teeth occurred only in the anterior regions and more frequently in the mandible than maxilla. Most of the congenitally missing teeth were mandibular lateral incisors $(78.8 \%)$, which was notably dissimilar to the findings of other studies in which it was mostly the maxillary lateral incisors that were missing [17, 20, 22, 23].

The prevalence of hypodontia in the primary dentition $(4.1 \%)$ was lower than that found in the permanent dentition (7.3\%) of southern Chinese children (Part I of this series of papers). Several studies have shown that about $75 \%$ to $100 \%$ of the cases of hypodontia in the primary dentition are followed by hypodontia in the permanent dentition in the same region [23-26]. Moreover, an association between hypodontia and ankylosis of primary molars, taurodontism, enamel hypoplasia and peg-shaped incisors has been reported in one study [27].

The prevalence of hypodontia found in the primary dentition of southern Chinese children (4.1\%) was much higher than for Japanese children $(0.2 \%$ and $2.4 \%)$ and Caucasians $(0-0.9 \%)$, see Table 2 . Differences between studies can arise from different sampling methods, the size and age of the study population, and the use of radiographs [28]. A further variable which is rarely highlighted is the race of the group under investigation. Variation in the racial prevalence of hypodontia in the primary dentition is suggestive of combined genetic and environmental components [29]. Thomsen [30] pointed out that differences in the prevalence of hypodontia were due to variations in gene frequency and the 
Table 4. The Prevalence of Microdontia in the Primary Dentition in Published Studies

\begin{tabular}{|c|c|c|c|}
\hline Ethnic Group and Location & Author & Number of Subjects Examined & Prevalence (\%) \\
\hline \multicolumn{4}{|l|}{ Southern Chinese } \\
\hline \multicolumn{4}{|l|}{ Mongoloid } \\
\hline Japan & Saito (1959) [2] & 7,589 & 0.2 (peg shaped) \\
\hline Japan & Ooshima et al. (1996) [3] & 905 & 1.2 (peg shaped) \\
\hline Japan & Yonezu et al. (1997) [4] & 2,733 & 0.6 \\
\hline \multicolumn{4}{|l|}{ Caucasian } \\
\hline U.K. & Brook (1974) [7] & 741 & 1.6 \\
\hline
\end{tabular}

Table 5. The Prevalence of Double Tooth in the Primary Dentition in Published Studies

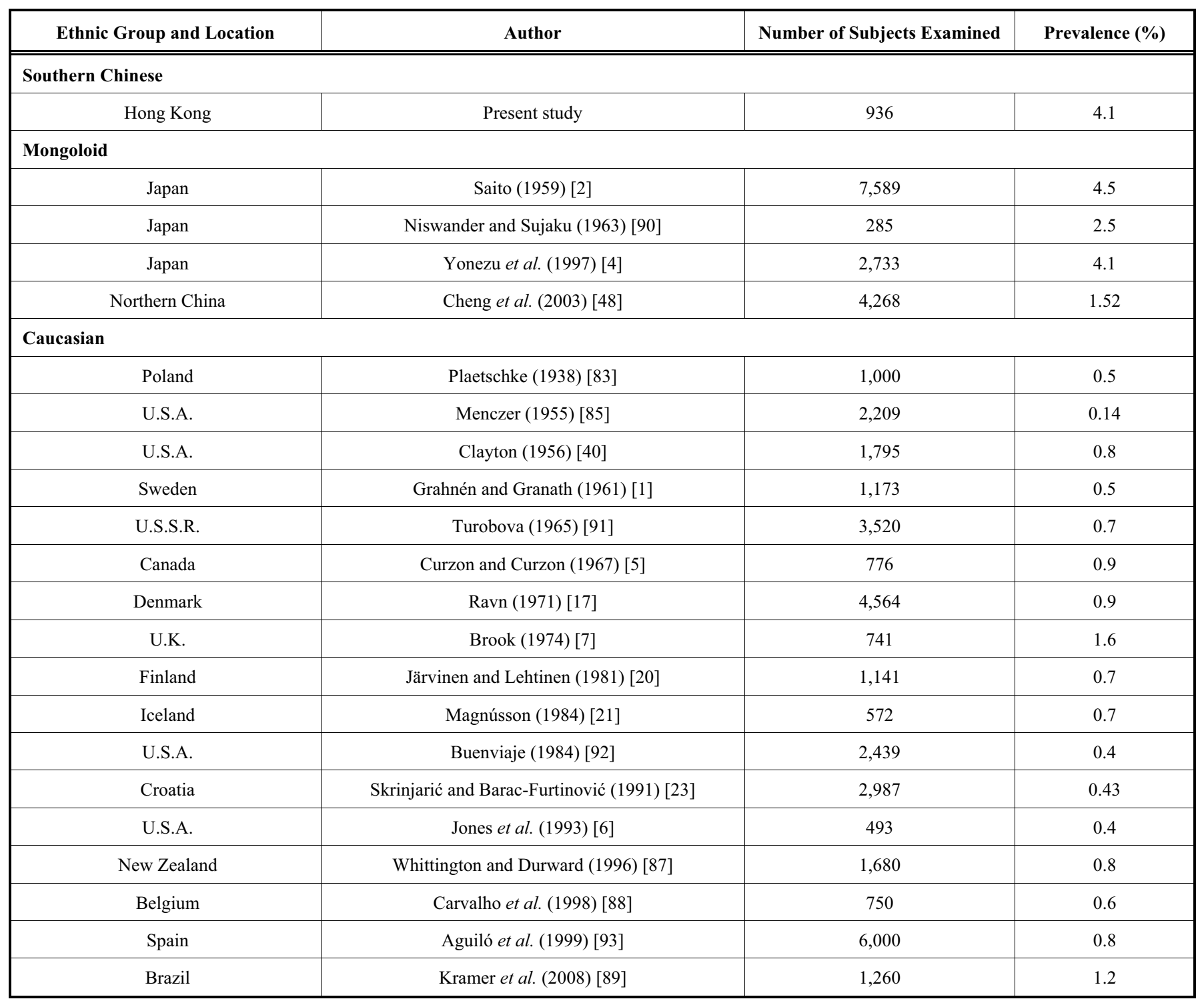


Table 6. The Frequency of Various Anomalies in the Primary Dentition of Southern Chinese People, other Mongoloid Groups and Caucasians

\begin{tabular}{|c|c|c|c|}
\hline Anomalies & Southern Chinese & Mongoloid (not southern Chinese) & low to moderate \\
\hline \hline Hypodontia & moderate & varied & low to moderate \\
\hline Hyperdontia & moderate & moderate \\
\hline Microdontia & high & moderate \\
\hline Macrodontia & moderate & low \\
\hline Double tooth & moderate & low \\
\hline Talon cusp & low & low to moderate \\
\hline Dens invaginatus & - & low \\
\hline Taurodontism & - & low \\
\hline
\end{tabular}

Chance of occurrence:

low: $\quad<1 \%$

moderate: $1 \%-5 \%$

high: $\quad>5 \%$

mode of inheritance which he suggested was autosomal recessive. More recent studies have identified genes that cause the absence of teeth in generations of non-syndrome patients. For example, mutations in the genes of MSX1 and PAX9 have been demonstrated to be associated with oligodontia in the posterior teeth and the mode of inheritance is autosomal dominant [31, 32]. Therefore, it is becoming increasingly evident that other genes probably play a role in hypodontia in different regions of the dental arches [33].

\section{Hyperdontia}

Hyperdontia refers to a dentition that has one, or more extra normal, or abnormal teeth. These teeth have been referred to as supernumerary, supplemental, extra, a third dentition, superdentition, aberrant, conoidal, paramolars, distomolars, mesiodens, and polyphodontism. These supernumerary teeth can arise as a result of splitting of the tooth germ [34], or extra budding of the dental lamina [35]. However, in most cases they are of an unknown aetiology.

As with hypodontia, hyperdontia in the primary dentition is rare. The quality of published data are affected by the sampling method; that is, whether the sample included patients referred for the evaluation of hyperdontia or its associated sequelae, the size of the population and whether or not radiographs were available. In addition, the age affects the data because any supernumerary teeth may have exfoliated or have been extracted during the late mixed dentition stage. The prevalence of hyperdontia in the primary dentition $(2.8 \%)$ was similar as that found in the permanent dentition $(2.6 \%)$ of southern Chinese children (Part I of this series of papers). Studies have shown that in $35 \%$ to $86 \%$ of cases with supernumerary primary teeth are followed by the presence of supernumerary permanent successors [23-26]. Nevertheless, hypodontia of the permanent dentition has also been reported to follow primary supernumerary teeth [25].

The predominance of boys among the southern Chinese with hyperdontia in this study (Table 1) was in agreement with the majority of other reports $[18-20,35,36]$, but contradictory to the findings of Brook [7], Luten [37], Ravn [17] and Humerfelt and co-workers [38] who found no difference between the gender, and Magnússon [21] who found that girls showed a higher prevalence than boys. All of the super- numerary teeth found in this study occurred in the maxilla which was in accordance with the findings of Ravn [17], Järvinen and Lehtinen [20], and Magnússon [21]. Almost all of these supernumerary teeth were unerupted $(97.0 \%)$, this was contrary to the findings of Luten [37] who reported that all of the supernumerary teeth in his study were erupted; and Humerfelt and co-workers [38] who reported that $73 \%$ of supernumerary teeth found in their study were erupted.

In southern Chinese, almost half of the supernumerary teeth $(48.5 \%)$ were observed along the midline (mesiodens). Apart from the mesiodens, the majority of supernumerary teeth occurred in the maxillary incisor region $(51.5 \%)$; by contrast Ravn [17], Järvinen and Lehtinen [20] and Humerfelt and co-workers [38] reported that hyperdontia in the primary dentition occurred most often in the lateral incisor regions (supplemental lateral incisors). The supernumerary teeth found in this study mostly had an inverted orientation rather than normal or transverse orientation $66.7 \%, 30.3 \%$ and $3.0 \%$ respectively, which is contrary to the findings of Huang and co-workers [35] who found that most mesiodens had a normal orientation. As normally orientated supernumerary teeth often erupt, the high prevalence of inverted teeth found in this study may explain why $97.0 \%$ of the supernumerary teeth were unerupted.

Several reports have indicated that there is a racial difference in the incidence of hyperdontia as shown in Table 3. The literature indicates a range from $0.1 \%$ to $1.8 \%$ for Caucasians. In populations of Mongolian origin, $0.1 \%$ was reported for Japanese while the mouth prevalence of hyperdontia for Chinese children, northern and southern Chinese combined, from a group of hospital patients in Taiwan was $7.8 \%$. The prevalence of hyperdontia was $2.8 \%$ for southern Chinese children in Hong Kong; however, no data are available to show if there is higher prevalence of hyperdontia for the northern Chinese children.

\section{Microdontia}

There are three types of microdontia; true generalized microdontia, relative generalized microdontia, both of which affect the entire dentition and thirdly, localized microdontia which involves only a single tooth [39]. 
True generalised microdontia, in which all of the teeth are smaller in size than normal, is extremely rare, such as in some cases of pituitary dwarfism. In relative generalized microdontia, normal or slightly smaller than normal teeth are present in jaws that are larger than normal, thus giving an illusion of microdontia. Localized microdontia is often associated with a tapering coronal form, making the anomaly relatively easy to identify [39].

In this study, microdontia occurred more frequently in the maxillary than the mandibular teeth and the canines were the most affected teeth. The subjects with microdontia, mostly had two symmetrically located microdont teeth. The prevalence of microdontia in southern Chinese children was $6.3 \%$ which was much higher than for other ethnic groups (Table 4). This high prevalence figure may have been because it included cone-shaped teeth, peg-shaped teeth and microdont canines, while the prevalence of $0.2 \%$ reported by Clayton [40] and Saito [2] were only for peg-shaped teeth. When considering the overall prevalence of $6.3 \%$, the majority of the teeth were microdont maxillary canines $(4.3 \%)$ which had no mesial marginal, or central ridge and had a shallow cingulum. This finding suggests that microdontia of the primary maxillary canines may be one of the characteristics of the southern Chinese dentition.

\section{Macrodontia}

Macrodontia, megalodontia, megadontia or gigantism occurs when a tooth, or teeth are larger than those considered to be within normal range; that is, they are outside the usual limits of variation. Macrodontia can be classified as true generalized, relative generalized and localized macrodontia in a manner similar to microdontia [39].

True generalized macrodontia, the condition in which all, or at least the majority of the teeth are larger than normal, has been associated with pituitary gigantism and hemihypertrophy; both conditions are extremely rare. Relative generalized macrodontia, which is slightly more common, is the result of the presence of normal or slightly larger than normal teeth in relatively small jaws. Localized macrodontia is when a single tooth exhibits normal crown, root and pulp morphology except for the size. A larger tooth with the presence of incisal notching, labial or palatal grooving, or supplemented by radiographic evidence of a separated or fused pulp chamber or root should be identified as a double tooth instead of macrodontia. As in microdontia, the importance of heredity factors must be considered [39].

There have been two epidemiological studies that sought to determine the prevalence of macrodontia in the primary dentition. In the study performed in the U.K., no examples of this anomaly were found [7]. In the study conducted in Japan, the criteria were defined as a large tooth, with 3.5 standard deviation above the sex-specific mean mesiodistal tooth size. In the study, macrodontia was found in $2.3 \%$ of the primary dentition and $1.9 \%$ of the permanent dentition, and the primary maxillary first molar was the most commonly affected tooth in Japanese children [3]. Using different examination criteria in the present study, the mouth prevalence for macrodontia of the southern Chinese children was $1.1 \%$ in the primary dentition and $3.6 \%$ in the permanent dentition (Part I of this series of papers). Macrodontia occurred only in the primary mandibular incisors and canines. Due to the rar- ity of this anomaly and the lack of prevalence data for the primary dentition, further studies on macrodontia in different populations are required.

\section{Double Tooth}

The terms fusion, gemination, twinning, connation, linking tooth, syodontia, schizodontia and dichotomy have also been proposed to describe a double tooth.

Hitchin and Morris [41] defined fusion as a result of the embryological persistence of the dental lamina between the two tooth buds, while Kelly [42] considered the same anomaly to be the result of an unsuccessful attempt of two tooth buds to fuse into one. Gemination has been proposed as the formation of two teeth from the same follicle and there is one common pulp chamber [42]. By contrast, the term "twinning" is said to indicate that the cleavage is complete, resulting in the formation of a supernumerary tooth that is usually a mirror image of its counterpart [39]. Because of the difficulty of formulating precise diagnoses and determining the aetiology for fusion, germination and twinning, the neutral term "double tooth" has been adapted by many investigators.

The double tooth anomaly, unlike most other anomalies, is more common in the primary dentition than the permanent dentition; for example, it was found in $4.1 \%$ in the primary dentition and $0.8 \%$ in the permanent dentition of southern Chinese children (Part I of this series of papers). It has been proposed that there may be an inter-relationship between primary and permanent double teeth [43]. Double tooth in the primary dentition has also been associated with disturbances in the permanent dentition varying from macrodontia, to enlargement of the contra-lateral tooth, to supernumerary teeth or even missing teeth [9]. In the primary dentition, double tooth has been reported to be associated with dens invaginatus [1], and conical shaped teeth [44].

The rarity of the double tooth anomaly in the primary posterior tooth was highlighted by no example being found in this study. Double teeth were found more frequently in the mandibular anterior canines and maxillary lateral incisors, which was in agreement with the findings of Hagman [45]. For purpose of making comparisons with other studies the double teeth in this study were reclassified into fusion and gemination based on the radiographic appearance of the root canals and pulp chambers; so $97.5 \%$ were examples of fusion and occurred mostly in the mandibular anterior teeth which is in agreement with the findings of Grahnén and Granath [1] and Ravn [17]; while 2.5\% were classified as gemination and involved the maxillary lateral incisors which is in agreement with the findings of von Hollaender [46]. However, it is difficult to be certain if there is fusion or germination without additional information obtained from histological examinations of a double tooth.

There is marked racial variation in the prevalence of the double tooth anomaly as shown in Table 5. Saito [2] reported that $4.5 \%$ of Japanese children had double teeth in their primary dentitions, but the data were for combined fused and congenitally absent teeth. This prevalence figure is similar to that reported for late prehistoric Mississippian populations (5\%) in North America [47]. Caucasians have generally been found to have a much lower prevalence of below 1\%. However, the prevalence of double tooth anomaly in the primary 
dentition of English children has been reported to be higher at $1.6 \%$ [7]. The prevalence of the double tooth in southern Chinese children is $4.1 \%$ which is two and a half times higher than found by Brook [7], in which the same diagnostic criteria were used. Interestingly, the prevalence in southern Chinese children was similar to that of Japanese $(4.5 \%$ and $4.1 \%$ ) reported by Saito [2] and Yonezu and co-workers [4], while it was much higher than that for northern Chinese children $(1.52 \%)$ [48].

\section{Talon Cusp}

Talon cusps are morphologically well delineated and extend at least half the distance from the cemento-enamel junction to the incisal edge of the primary teeth. This dental anomaly was firstly described as a process of horn-like shape curving from the base to the cutting edge on the palatal surfaces of the incisors [49]. Mellor and Ripa [50] proposed the term talon cusp because they considered that the shape of the anomaly resembled an eagle's talon. It has also been referred to as a cusp-like projection, hyperplasia of the cingulum, palatal accessory cusp and unusual projection of the facial surface of the anterior teeth. One cause may be hyperactivity of the dental lamina, which occurs most commonly in the anterior region [51].

Since this anomaly is extremely rare in the primary dentition, very few reports have been published on talon cusp in the primary dentition of non-cleft and non-syndrome subject. A case of a supplemental primary maxillary left lateral incisor in association with bilateral talon cusps in primary maxillary central incisors has been reported [52]. It has also been suggested that the morphology and number of permanent successors can be affected by a talon cusp on the primary predecessor. Children who had a talon cusp on a primary incisor have been reported to have hyperdontia, hypodontia or a talon cusp affecting their permanent anterior teeth [5359]. This association has also occurred in children with cleft lip and /or palate [60] and in a patient suffering from hypomelanosis [61]. Moreover, it has been proposed that a talon cusp on a primary maxillary central, or a lateral incisor has a different effect on the corresponding permanent successor, particularly with respect to the number of successor teeth. In a study conducted in Hong Kong of Chinese children with talon cusps on their maxillary central incisors; $8.6 \%$ of them had odontogenic abnormalities associated with their permanent successors. When the lateral incisors had talon cusps, $78.3 \%$ showed odontogenic abnormalities and $61 \%$ were associated with supernumerary teeth [49].

The vast majority of studies on the prevalence of talon cusp have involved the permanent dentition and rarely on the primary dentition. The prevalence of talon cusp in a group of American children aged 2-12 years was reported to be $0.17 \%$; however, the authors did not mention whether the anomaly was related to the primary or permanent dentition. A study of Japanese children found that the prevalence of talon cusp in the permanent dentition was $0.9 \%$ while that in the primary dentition was $0.6 \%$ [3]. Although it has been suggested that the incidence of talon cusp in the primary dentition may not be lower than that in the permanent dentition [53, 62], the mouth prevalence of talon cusp in southern Chinese found in this series of studies was $2.5 \%$ in the permanent dentition but only $0.5 \%$ in the primary dentition. A review of the literature by al-Omari and colleagues [63] also revealed that permanent teeth are affected with talon cusp three times more frequently than primary teeth, and males are more frequently affected than females in a ratio of 3.5:1 in the primary dentition. Lee and his co-workers [58] reported that the male:female ratio of talon cusp in the primary dentition was 1.9:1 in Hong Kong, which is similar to the ratio of 1.8:1 which was calculated from all of the 39 cases reported in the English literature; it is noteworthy that 20 were Chinese, 7 Japanese, 11 non-mongoloids and the ethnic origin of one cases was unspecified. The higher male predilection may suggest a sex-linked genetic component in the aetiology of talon cusp in the primary dentition. However, this difference in gender was not found in the present study, see Table 1.

\section{Dens Invaginatus}

Salter [64] who is credited as with being the first person to report a case of what is now known as dens invaginatus and he labelled this dental anomaly with "warty tooth". This anomaly has also been referred to as dens in dente, because it was believed that this phenomenon resulted from one tooth surrounding another during the process of growth [64]. Tomes [65] first defined this anomaly as an infolding of the enamel and dentin towards the pulp. He stated that the defective tooth was usually irregular in shape and that the enamel investing the crown could be perfectly developed, but there may be a slight depression in the crown; the dark centre of which represents the blocked orifice of a cavity within the tooth. Histologically sections, the exterior enamel can be followed through into the orifice where it lines the surface of the cavity.

Dens invaginatus is rare in the primary dentition [66]. The only prevalence study was conducted by Brook [7], who reported the prevalence of this anomaly for English children in Slough to be $0.1 \%$, with no gender variation [7]. Apart from this study, there were only four case reports of dens invaginatus in the primary dentition. Dens invaginatus has been observed in the primary canine, maxillary central incisor, and mandibular second molar [67-70]. All of the documented case reports involve males, if this a true reflection of this anomaly then it contrasts with the permanent dentition where females appear to be more at risk [71] or possibly there is no gender difference [72]. There are no reports of primary lateral incisors being invaginated, unlike their permanent counterparts, which are the most commonly tooth affected [73].

The apparent low prevalence of dens invaginatus in the primary dentition, zero in this study and $0.1 \%$ by Brook [7], could be due to variations in the examination methodology, the sampling method or sample size; the quality of the radiographs, the use of slightly different diagnostic criteria and classifications. The diagnosis is difficult to make clinically and even radiographically and in this regard Gotoh and coworkers [74] suggested that extracted teeth should be used.

\section{Taurodontism}

When a tooth exhibits taurodontism there is a tendency for the body of the tooth to be enlarged at the expense of the roots [75], so it can be confirmed radiographically as the tooth tends to be more rectangular in shape. The pulp chamber is enlarged, especially vertically and the tooth also lacks the usual cervical constriction [76]. This anomaly is of inter- 
est to anthropologists in the determination of the evolution of man $[77,78]$. There are very few published diagnostic criteria for primary teeth so those for permanent teeth are usually applied; however, Jørgensen [79] discounted the classification of Shaw [77] as being inapplicable for the primary dentition. He suggested a classification specially for the primary dentition which identified two types. Type I being when the height of the root stem, the vertical distance between the amelo-cemental junction and the most apical point of the root bifurcation, is less than $2.5 \mathrm{~mm}$; while Type II is when the height of the root stem is more than $2.5 \mathrm{~mm}$. However, this system is dependent on the overall dimension of the tooth.

The diagnostic criteria of Daito and Heida [80] for primary teeth is based on the ratio between the crown height and the root stem. The teeth are subclassified as hypotaurodont, mesotaurodont, or hypertaurodont when the ratio is $1: 0.3$ to $0.5,1: 0.5$ to 1.0 , or $1: 1.0$ or greater, respectively. Although overcoming the problems related to the teeth being small, occlusal attrition affects the results when this system is applied. However, these problems can be avoided by using the relatively simple metric criteria, for the permanent dentition, developed by Holt and Brook [12], in which the ratio of the length of the root stem and the overall root length indicate taurodontosm when the ratio is $1: 4.5$ or less. This is why this technique was used in the current study.

Taurodontism is most evident in the mandibular molars and the occurrence can be unilateral or bilateral. Among the sinanthropus pekinensis cases studied by Weidenreich [81], there was only one in which the primary mandibular second molar exhibited taurodontism. Even in the modern literature only limited data are available for taurodontism in the primary dentition and unfortunately they mostly come from case reports [13]. The reported prevalence data for taurodontism in the primary dentition are $0.5 \%$ for Japanese children [80] and $0.08 \%$ for northern Europeans of unspecified national background [82]. Jørgensen [79] reported a prevalence of $9.0 \%$ among modern Danes, which is extremely high. Although taurodontism is known to occur in the southern Chinese, the rarity of taurodontism in the primary molars of southern Chinese was confirmed by no example being found in this study. However, this can be partly attributed to the diagnostic criteria and the inaccuracies of using a panalipse radiograph. Further studies to establish standardized criteria and the collection of large quantities of source material are required for taurodontism in the primary dentition.

Although, as a result of this study, data have been complied on the prevalence of the various dental anomalies in the primary dentition of southern Chinese children, the limited published literature about these characteristics in the primary dentition indicates that there is a need for further research in this field to provide initially, higher quality prevalence data and subsequently to supplement the anthropologic significance of the dental anomalies that have been observed in the primary teeth of the southern Chinese children.

\section{CONCLUSION}

From the findings of this study it was determined that southern Chinese children have a higher prevalence of hypodontia, hyperdontia, microdontia, and double tooth in the primary dentition than Caucasians. The prevalence figures for microdont maxillary canines and missing lateral mandibular incisors were so high that it may be appropriate to consider these anmalies as being characteristics of the southern Chinese dentition. In part IV of this series it is proposed to consider various traits of the primary dentition of southern Chinese children.

\section{REFERENCES}

[1] Grahnén H, Granath LE. Numerical variations in primary dentition and their correlation with the permanent dentition. Odont Revoy 1961; 12: 348-57.

[2] Saito T. A genetic study on the degenerative anomalies of deciduous teeth. Jap J Hum Genet 1959; 4: 27-53.

[3] Ooshima T, Ishida R, Mishima K, Sobue S. The prevalence of developmental anomalies of teeth and their association with tooth size in the primary and permanent dentitions of 1650 Japanese children. Int J Paediatr Dent 1996; 6: 87-94.

[4] Yonezu T, Hayashi Y, Sasaki J, Machida Y. Prevalence of congenital dental anomalies of the deciduous dentition in Japanese children. Bull Tokyo Dent Coll 1997; 38: 27-32.

[5] Curzon JA, Curzon MEJ. Congenital dental anomalies in a group of British Columbian children. J Can Dent Assoc 1967; 33: 554-8.

[6] Jones ML, Mourino AP, Bowden TA. Evaluation of occlusion, trauma and dental anomalies in African-American children of metropolitan Headstart programs. J Clin Pediatr Dent 1993; 18: 51-4.

[7] Brook AH. Dental anomalies of number, form and size: their prevalence in British schoolchildren. J Int Assoc Dent Child 1974; 5: 37 53.

[8] Moorrees CFA. The dentition of the growing child. A longitudinal study of dental development between 3 and 18 years of age. Vambridge, MA: Harvard University Press 1959.

[9] Brook AH, Winter GBW. Double teeth: a retrospective study of "geminated" and "fused" teeth in children. Br Dent J 1970; 129: 123-30.

[10] Davis PJ, Brook AH. The presentation of talon cusp: duagnosis, clinical features, associations and possible aetiology. Br Dent J 1985; 160: 84-8.

[11] Hallet GEM. The incidence, nature and clinical significance of palatal invaginations in the maxillary incisor teeth. Proc R Soc Med 1953; 46: 491-9.

[12] Holt RD, Brook AH. Taurodontism: a criteria of diagnosis and its prevalence in mandibular first permanent molars in the sample of 115 British school children. Int Assoc Dent Child 1979; 10: 41-7.

[13] Jafarzadeh H, Azarpazhooh A, Mayhall JT. Taurodontism: a review of the condition and endodontic treatment challenges. Int Endod J 2008; 41(5): 375-88.

[14] Grewal MS. The development of an inherited tooth defect in the mouse. J Embryol Exp Morph 1962; 10: 202-11.

[15] Sofaer JA, Chung CS, Niswander JD, Runck DW. Developmental interaction, size and agenesis among permanent maxillary incisors. Hum Biol 1971; 43: 36-45.

[16] Gorlin RJ, Pindborg JJ, Cohen MM. Syndromes of the head and neck. McGraw-Hill Book Co: New York, USA 1978.

[17] Ravn JJ. Aplasia, supernumerary teeth and fused teeth in the primary dentition. Scand J Dent Res 1971; 79: 1-6.

[18] Holm AK, Arvidsson S. Oral health in preschool Swedish children. Odont Revoy 1974; 25: 81-97.

[19] Rasmussen I, Helm S. Forekomsten af tandstillingsfeil i det primære tandsæt. Tandlægebladet 1975; 79: 383-8.

[20] Järvinen S, Lehtinen L. Supernumerary and congenitally missing primary teeth in Finnish children. Acta Odont Scand 1981;39: 83-6.

[21] Magnússon TE. Hypodontia, hyperdontia, and double formation of primary teeth in Iceland. An epidemiological study. Acta Odont Scand 1984; 42: 137-9.

[22] Brabant H. Comparison of the characteristics and anomalies of the deciduous and the permanent dentition. J Dent Res 1967; 46: 897901.

[23] Skrinjarić I, Barac-Furtinović V. Anomalies of deciduous teeth and findings in permanent dentition. Acta Stomatol Croat 1991; 25(3): 151-6.

[24] Winter GB, Brook AH. Tooth abnormalities. In: Clinical Dentistry, Rowe AHR, Alexander G, John B, Eds. Blackwell Scientific Publications, 1986; 55-103. 
[25] Gellin ME. The distribution of anomalies of primary anterior teeth and their effect on the permanent tsuccessors. Dent Clin North Am 1984; 28: 69-80.

[26] Nik-Hussein NN, Abdul Majid Z. Dental anomalies in the primary dentition: distribution and correlation with the permanent dentition. J Clin Pediatr Dent 1996; 21(1): 15-9.

[27] Lai PY, Seow WK. A controlled study of the association of various dental anomalies with hypodontia of permanent teeth. J Pediatr Dent 1989; 11: 291-6.

[28] Lervik T, Cowley CG. Observations of dental disease and anomalies in 9- to 11-year-old Norwegian children. Acta Odont Scand 1983; 41: 45-51.

[29] Zengin AZ, Sumer AP, Karaarslan E. Impacted primary tooth and tooth agenesis: a case report of monozygotic twins. Eur J Dent 2008; 2(4): 299-302.

[30] Thomsen S. Missing teeth with special reference to the population of Tristan da Cunha. Am J Phys Anthropol 1952; 10: 155-67.

[31] Klein ML, Nieminen P, Lammi L, Niebuhr E, Kreiborg S. Novel mutation of the initiation codon of PAX9 causes oligodontia. J Dent Res 2005; 84: 43-7.

[32] Kapadia H, Mues G, D'Souza R. Genes affecting tooth morphogenesis. Orthod Craniofac Res 2007; 10(4): 237-44.

[33] Wang $\mathrm{Y}, \mathrm{Wu} \mathrm{H}, \mathrm{Wu} \mathrm{J}$, et al. Identification and functional analysis of two novel PAX9 mutations. Cells Tissues Organs 2009; 189(14): 80-7.

[34] Yusof WZ. Non-syndrome multiple supernumerary teeth: literature review. J Cand Dent Assoc 1990; 56: 147-9.

[35] Huang WH, Tsai TP, Su HL. Mesiodens in the primary dentition stage: a radiographic study. J Dent Child 1992; 59: 186-9.

[36] Moller P. Oral health survey of preschool children in Iceland. Acta Odont Scand 1963; 21; 47-97.

[37] Luten JR. The prevalence of supernumerary teeth in primary and mixed dentitions. J Dent Child 1967; 34: 346-53.

[38] Humerfelt D, Hurlen B, Humerfelt S. Hyperdontia in children below four years of age: a radiographic study. J Dent Child 1985; 52: 121-4.

[39] Shafer WG, Hine MK, Levy BM. A textbook of oral pathology. $4^{\text {th }}$ ed. Philadelphia: WB Saunders Co 1983.

[40] Clayton JM. Congenital dental anomalies occurring in 3357 children. J Dent Child 1956; 23: 206-8.

[41] Hitchin AD, Morris I. Geminated odontome -connation of the incisors in the dog-its etiology and ontogeny. J Dent Res 1966; 45: 575-83.

[42] Kelly J. Gemination, fusion or both? Oral Surg Oral Med Oral Pathol 1978; 45: 655-6.

[43] Erdem GB, Uzamis M, Ölmez S, Sargon MF. Primary incisor triplication defect. J Dent Child 2001; 68: 322-5.

[44] Burley MA, Reynolds CA. Gemination of three anterior teeth. $\mathrm{Br}$ Dent J 1965; 118: 169-70.

[45] Hagman FT. Anomalies of form and number, fused primary teeth, a correlation of the dentitions. J Dent Child 1988; 55: 359-61.

[46] von Hollaender K. Klinisch-roentgenologisisch Untersuchung von drei Geschwistern mit Doppelbildung von Mitchfrontzaehnen. Dtsch Zahnartzl Z 1980; 35: 831-4.

[47] Stevenson DR. Prevalence rate of double teeth in the deciduous dentition at Averbuch (40 DV 60). Tenn Anthropol 1985; 10: 13455.

[48] Cheng RB, Chen X, Liu SJ, Pan L, Wu XG. An epidemiological survey on fusion of deciduous teeth of 4286 kindergarten children in Shenyang city. Shanghai Kou Qiang Yi Xue 2003; 12(6): 424-6.

[49] Mitchell WH. Case report. Dent Cosmos 1892; 34: 1036.

[50] Mellor JK, Ripa LW. Talon cusp: a clinically significant anomaly. Oral Surg Oral Med Oral Pathol 1970; 29: 225-8.

[51] Rantanen AV. Talon cusp. Oral Surg 1971; 32: 398-400.

[52] Hattab FN, Yassin OM. Bilateral talon cusps on primary central incisors: a case report. Int J Paediatr Dent 1996; 6: 191-5.

[53] Chen RJ, Chen HS. Talon cusp in primary dentition. Oral Surg Oral Med Oral Pathol 1986; 62: 67-72.

[54] Reddy VVS, Mehta DS. Talon cusp in primary lateral incisor: report of a case. J Indian Soc Pedod Prev Dent 1989; 7: 20-2.

[55] Acs G, Pokala P, Cozzi E. Shovel incisors, three-rooted molars, talon cusp, and supernumerary tooth in one patient. Pediatr Dent 1992; 14: 263-4.

[56] Tiku A, Nadkarni UM, Damle SG. Management of two unusual cases of dens invaginatus and talon cusp associated with other dental anomalies. J Indian Soc Pedod Prev Dent 2004; 22: 128-33.
[57] Mays S. Talon cusp in a primary lateral incisor from a medieval child. Int J Paediatr Dent 2005; 15: 67-72.

[58] Lee CK, King NM, Lo EC, Cho SY. Talon cusp in the primary dentition: literature review and report of three rare cases. J Clin Pediatr Dent 2006; 30(4): 299-305.

[59] Lee CK, King NM, Lo EC, Cho SY. The relationship between a primary maxillary incisor with a talon cusp and the permanent successor: a study of 57 cases. Int J Paediatr Dent 2007; 17(3): 178-85.

[60] Bøhn A. Anomalies of the lateral incisor in cases of harelip and cleft palate. Acta Odontol Scand 1950; 9: 41-59.

[61] Happle R, Vakilzadeh F. Hamartomatous dental cusps in hypomelanosis of lto. Clin Genet 1982; 21: 65-8.

[62] Liu JF, Chen LR. Talon cusp affecting the primary maxillary central incisors in two sets of female twins: report of two cases. Pediatr Dent 1995; 17: 362-4.

[63] al-Omari MA, Hattab FN, Darwazeh AM, Dummer PM. Clinical problems associated with unusual cases of talon cusp. Int Endod J 1999 32: 183-90.

[64] Salter SJA. Warty tooth. Transact Pathol Soc Lond 1855; 6: 173-7.

[65] Tomes J. Description of an inverted tooth and the consequences which its inversion entailed, considered in relation to certain forms of tumours of the jaw. Br Dent J Sc II 1858-1859: 146-8.

[66] Pindborg JJ. Pathology of the Dental Hard Tissues. Copenhagen, Munksgaard 1970.

[67] Rabinowitch BZ. Dens in dente: primary tooth-report of a case. Oral Surg Oral Med Oral Pathol 1952; 5: 1312-4.

[68] Holan G. Dens invaginatus in a primary canine: a case report. Int J Paediatr Dent 1998; 8: 61-4.

[69] Kupietzky A. Detection of dens invaginatus in a one-year old infant. Pediatr Dent 2000; 22, 148-50.

[70] Eden EK, Koca H, Sen BH. Dens invaginatus in a primary molar: report of case. J Dent Child 2001; 69, 49-53.

[71] Thongudomporn U, Freer TJ. Prevalence of dental anomalies in orthodontic patients. Aust Dent J 1998; 43:395-8.

[72] Hamasha AA, Al-Omari QD. Prevalence of dens invaginatus in Jordanian adults. Int Endo J 2004; 37: 307-10.

[73] Hülsmann M. Dens invaginatus: aetiology, classification, prevalence, diagnosis, and treatment considerations. Int Endo J 1997; 30: 79-90.

[74] Gotoh T, Kawahara K, Imai K, Kishi K, Fujiki Y. Clinical and radiographic study of dens invaginatus. Oral Surg Oral Med Oral Pathol 1979; 48: 88-91.

[75] Keith A. Problem relating to the teeth of earlier forms of prehistoric man. Proc R Soc Med 1913; 6: 103-10.

[76] Ogden G. The significance of taurodontism in dental surgery. Dent Update 1988; 15:32-4

[77] Shaw JC. Taurodont teeth in South Africa races. J Anat 1928; 62: 476-99.

[78] Jorgensen RJ. The conditions manisfesting taurodontism. Am J Med Genet 1982; 11: 435-42.

[79] Jørgensen KD. The deciduous dentition: a descriptive and comparative anatomical study. Acta Odont Scand 1956; 14(Suppl 20): $1-202$.

[80] Daito M, Heida T. Taurodont teeth in primary dentition. Jpn J Pedodont 1971; 9: 93-106.

[81] Weidenreich F. The dentition of Sinanthropus pekinensis: a comparative odontography of the hominids. Palaeont Sinica 1937; 10.

[82] Sicher H. Orban's oral history and embryology. St Louis: Mosby 1962.

[83] Plaetschke J. Okklusionsanomalien im milchgebiss. Dtsch Zahn, Mund-u Kieferheilk 1938; 5:435.

[84] Leighton BC. Some abnormalities of the deciduous dentition. Dent Res 1953; 43: 395-401.

[85] Menczer LF. Anomalies of the primary dentition. J Dent Child 1955; 22: 57-62.

[86] Hanusardóttir B. Skeivar tenn jhá føroyskum børnum. Fróõskaparrit (Annual Societ Scient Færóensis) 26, bøk, Tørshavn 1978.

[87] Whittington BR, Durward CS. Survey of anomalies in primary teeth and their correlation with the permanent dentition. N Z Dent J 1996; 92: 4-8.

[88] Carvalho JC, Vinkler F, Declerck D. Malocclusion, dental injuries and dental anomalies in the primary dentition of Belgian children. Int J Paediatr Dent 1998; 8: 137-41.

[89] Kramer PF, Feldens CA, Ferreira SH, Spiguel MH, Feldens EG. Dental anomalies and associated factors in 2- to 5-year-old Brazilian children. Int J Paediatr Dent 2008; 18(6): 434-40. 
[90] Niswander JD, Sujaku C. Congenital anomalies of teeth in Japanese children. Am J Phys Anthropol 1963; 21: 569-74.

[91] Turobova GA. K voprosu ob anomalii formy molochnykh zubov. Stomatologiya (Mosk) 1965; 44: 86-8.

[92] Buenviaje TM, Rapp R. Dental anomalies in children: a clinical and radiographic survey. Dent Child 1984; 51: 42-6.

(C) King et al.; Licensee Bentham Open.

This is an open access article licensed under the terms of the Creative Commons Attribution Non-Commercial License (http://creativecommons.org/licenses/by-nc/3.0/) which permits unrestricted, non-commercial use, distribution and reproduction in any medium, provided the work is properly cited.

retrospective clinical study of their morphological characteristics and associated anomalies. Int J Paediatr Dent 1999; 9(3): 175-83. 